\title{
陕西省森林各生态系统组分氮磷化学计量特征
}

\author{
崔高阳 ${ }^{1}$ 曹 扬 ${ }^{2,3}$ 陈云明 $2,3^{*}$ \\ ${ }^{1}$ 中国科学院教育部水土保持与生态环境研究中心, 陕西杨凌 $712100 ;{ }^{2}$ 西北农林科技大学黄土高原土壤侵蚀与旱地农业国家重点实验室, 陕西杨凌 \\ $712100{ }^{3}$ 中国科学院水利部水土保持研究所, 陕西杨凌 712100
}

摘 要 研究森林植被、枯落物和土壤的氮 $(\mathrm{N})$ 磷 $(\mathrm{P})$ 化学计量关系对于理解生态系统各组分的相互作用和养分循环具有重要 意义。该研究对陕西省不同类型森林生态系统植被、枯落物和土壤的 $\mathrm{N}$ 和 $\mathrm{P}$ 含量及其化学计量关系进行了研究分析。结果表 明: 1)森林生态系统各组分的 $\mathrm{N} 、 \mathrm{P}$ 化学计量特征存在显著差异 $(p<0.05), \mathrm{N} 、 \mathrm{P}$ 含量均以林下灌草层植物和枯落物层较高, 乔 木层植物和土壤层较低; $\mathrm{N}: \mathrm{P}$ 值则稍有不同, 以枯落物层最高, 土壤层最低, 其他各层差异不显著; 各组分 $\mathrm{N} 、 \mathrm{P}$ 含量和 $\mathrm{N}: \mathrm{P}$ 值分 别为0.72-11.99 mg $\cdot \mathrm{g}^{-1} 、 0.47-1.07 \mathrm{mg} \cdot \mathrm{g}^{-1}$ 和1.86-14.84。0-1 m土层内 $\mathrm{N}$ 含量、 N:P值均随土层加深而降低 $(p<0.05), \mathrm{P}$ 含量则不 随土层发生明显变化。2)各组分 $\mathrm{N} 、 \mathrm{P}$ 含量和 $\mathrm{N}: \mathrm{P}$ 值多表现为阔叶林高于针叶林, 但其差异不显著。3)生态系统同一组分内, N、 $\mathrm{P}$ 含量间极显著正相关, $\mathrm{N} 、 \mathrm{P}$ 含量与 $\mathrm{N}$ : $\mathrm{P}$ 值分别呈极显著正相关、负相关关系, 但是土壤层内 $\mathrm{N} 、 \mathrm{P}$ 含量无显著相关关系。各组 分间, 枯落物层与乔木层、草本层和土壤层的 $\mathrm{N} 、 \mathrm{P}$ 含量和 $\mathrm{N}: \mathrm{P}$ 值也均极显著正相关, 而枯落物层与灌木层植物无显著相关关 系。4)生态系统各组分 $\mathrm{N} 、 \mathrm{P}$ 含量和 $\mathrm{N}: \mathrm{P}$ 值随空间变化表现不尽一致, 总体上呈稳态。该文通过对 $\mathrm{N} 、 \mathrm{P}$ 化学计量特征的研究, 揭 示了森林生态系统植被、枯落物和土壤组分间所存在的养分循环联系, 这些联系中也表现出分异特征, 而分异可能由各自所 执行的不同生态功能所致。

关键词 氮, 磷, 森林生态系统, 针叶林, 阔叶林, 空间变化

引用格式: 崔高阳, 曹扬, 陈云明 (2015). 陕西省森林各生态系统组分氮磷化学计量特征. 植物生态学报, 39, 1146-1155. doi: 10.17521/cjpe.2015.0111

\section{Characteristics of nitrogen and phosphorus stoichiometry across components of forest eco- system in Shaanxi Province}

\author{
CUI Gao-Yang ${ }^{1}$, CAO Yang ${ }^{2,3}$, and CHEN Yun-Ming, ${ }^{2,3 *}$ \\ ${ }^{1}$ Research Center of Institute of Soil and Water Conservation and Ecological Environment, Chinese Academy of Sciences and Ministry of Education, Yangling, \\ Shaanxi 712100, China; ${ }^{2}$ State Key Laboratory of Soil Erosion and Dryland Farming on Loess Plateau, Northwest A\&F University, Yangling, Shaanxi 712100, \\ China; and ${ }^{3}$ Institute of Soil and Water Conservation, Chinese Academy of Sciences and Ministry of Water Resources, Yangling, Shaanxi 712100, China
}

\section{Abstract}

Aims Nitrogen (N) and phosphorus (P) stoichiometry between vegetation, litter, and soil were important for understanding biogeochemical cycles in terrestrial ecosystems, but remain poorly understood. Here, our aims were to study characteristics of $\mathrm{N}$ and $\mathrm{P}$ stoichiometry for the plant, litter, and soil and the interactions between its components across forest ecosystems in Shaanxi Province.

Methods A total of 121 sampling sites, covering the most main forest types in Shaanxi, were established across the whole province in 2012. And $\mathrm{N}$ and P concentration of vegetation (tree and understory), litter and soil layers were measured for each site.

Important findings 1) There were significant differences in the $\mathrm{N}$ and $\mathrm{P}$ stoichiometry among the forest ecosystem components $(p<0.05)$. $\mathrm{N}$ and $\mathrm{P}$ contents were higher in understory and litter layer, and lower in tree and soil. Whereas the N:P was slightly different, highest in litter and lowest in the soil layer, with little differences among remaining components. The contents of $\mathrm{N}, \mathrm{P}$ and $\mathrm{N}: \mathrm{P}$ ranged from 0.72 to11.99 $\mathrm{mg} \cdot \mathrm{g}^{-1}, 0.47$ to $1.07 \mathrm{mg} \cdot \mathrm{g}^{-1}$, and 1.86 to 14.84 , respectively. Within top $1 \mathrm{~m}$ soil layer $\mathrm{N}$ content and $\mathrm{N}$ :P decreased with soil depth $(p<0.05)$, however the P content did not exhibit significant changes. 2) $\mathrm{N}$ and $\mathrm{P}$ contents, and $\mathrm{N}: \mathrm{P}$ of each component were higher in broadleaf forest than in coniferous forest, although the difference is not significant. 3) N was positively correlated with $\mathrm{P}$ content except for soil and $\mathrm{N}: \mathrm{P}$ was negatively correlated with $\mathrm{P}$ content, but positively correlated with $\mathrm{N}$ content within each component. In addition, there was a significant positive correlation for $\mathrm{N}$ and $\mathrm{P}$

收稿日期Received: 2015-04-28 接受日期Accepted: 2015-10-24

* 通讯作者Author for correspondence (E-mail: ymchen@ms.iswc.ac.cn) 
stoichiometric characteristics between litter layer and tree, herb, soil layer. 4) Although spatial pattern of $\mathrm{N}$ and $\mathrm{P}$ contents, and N:P differed in relation to longitude, latitude, and elevation for forest ecosystem components, a stable distribution was exhibited in general.

Key words N, P, forest ecosystem, coniferous forest, broadleaf forest, spatial variation

Citation: Cui GY, Cao Y, Chen YM (2015). Characteristics of nitrogen and phosphorus stoichiometry across components of forest ecosystem in Shaanxi Province. Chinese Journal of Plant Ecology, 39, 1146-1155. doi: 10.17521/cjpe.2015.0111

生态化学计量学作为一门研究生态系统中能量 平衡和多重化学元素平衡的科学, 把生态学中不同 层次的研究理论有机地统一起来, 是实现对复杂系 统进行本质认识的有效工具(Elser et al., 2000b)。氮 (N)和磷 (P) 作为植物体的基本组成元素和生态系统 过程重要的影响因素, 对生态系统的结构和功能有 着重要的作用。借助于生态化学计量学这一研究工 具开展生态系统N、P养分分布(Li et al., 2010; Chen et al., 2013)、循环(Manzoni et al., 2010)及养分限制 指示(Bott et al., 2008; Wang \& Moore, 2014)等研究, 对于揭示生态系统过程影响因素及其作用机制具有 重要意义。

目前有关森林生态系统N、P化学计量的研究主 要集中于叶片和细根尺度。例如: 任书杰等(2007)、 Han等(2005)、Reich和Oleksyn (2004)、Ordoñez等 (2009)等, 分别在区域乃至全球范围内对叶片 $\mathrm{N} 、 \mathrm{P}$ 化学计量空间分布格局进行了研究; Yuan等(2011) 分析研究了全球细根N、P养分的纬度分布模式; 此 外, 也有学者对土壤 $N 、 P$ 化学计量特征进行了大量 的研究(Cleveland \& Liptzin, 2007; Tian et al., 2010; Yuan \& Chen, 2012)。这些研究对丰富生态系统化学 计量特征起到了关键作用。综合来看, 这些研究一 般只针对生态系统的单一组分 (土壤或植被)、器官 (植物叶片或细根等)开展 $\mathrm{N} 、 \mathrm{P}$ 化学计量研究, 未能 将生态系统各组分统一起来综合研究各组分之间的 $\mathrm{N} 、 \mathrm{P}$ 化学计量特征。目前, 在生态系统尺度上, 将 植被、枯落物和土壤作为一个整体来系统研究 $N 、 P$ 化学计量特征及其关系的工作还较少 (王绍强和于 贵瑞, 2008), 且尚不清楚生态系统水平化学计量学 特征是否与一般植物叶片表现出相似的变化规律。 而揭示森林植被、枯落物和土壤各组分间的化学计 量特征及其相互关系和空间变异, 能够帮助我们进 一步深入认识系统物质养分循环及其作用机制, 加 深对氮磷生物地球化学循环的理解。因此, 本文对 陕西省不同类型森林生态系统各组分(植被、枯落
物、土壤) $\mathrm{N} 、 \mathrm{P}$ 化学计量特征及其空间分布进行了 分析, 以期探明生态系统尺度上化学计量特征及其 各组成成分间的相互联系, 深入认识植物-枯落物土壤相互作用的养分调控机制和氮磷元素之间的相 互作用及平衡制约关系。

一般来说, 植物、枯落物和土壤作为生态系统 物质循环和能量流动的主要储存库和周转环节, 彼 此间存在着结构和功能间的紧密联系。因此我们预 测, 森林生态系统各组分 $\mathrm{N} 、 \mathrm{P}$ 化学计量特征同样也 存在着紧密的联系, 但由于各组分在养分物质的循 环中扮演着不同角色, 其 $\mathrm{N} 、 \mathrm{P}$ 化学计量关系理应有 所差异。鉴于本研究中具有不同性质的3种主要森林 类型(即: 栓皮栋(Quercus variabilis)落叶阔叶林、油 松(Pinus tabuliformis)常绿针叶林和豆科植物占优 势的刺槐(Robinia pseudoacacia)林)生理生态功能的 差异, 我们预测刺槐林 $\mathrm{N} 、 \mathrm{P}$ 含量应高于其他两种林 分, 但3种林型间的 $\mathrm{N}: \mathrm{P}$ 值差异可能较小。

\section{1 材料和方法}

\section{1 研究区概况及样地设置}

陕西省位于中国西北部 $\left(105.50^{\circ}-111.25^{\circ} \mathrm{E}\right.$, $\left.31.70^{\circ}-39.60^{\circ} \mathrm{N}\right)$, 地跨北温带和亚热带, 整体属大 陆季风性气候, 年降水量 $576.9 \mathrm{~mm}$, 年平均气温 $13.0{ }^{\circ} \mathrm{C}$, 无霜期 218 天左右。境内南北间气候差异明 显, 长城沿线以北为温带干旱半干旱气候, 陕北其 余地区和关中平原为暖温带半湿润气候, 陕南盆地 为北亚热带湿润气候, 山地大部为暖温带湿润气 候。植被类型由暖温带湿润半湿润森林带向中温带 干旱半干旱荒漠草原过渡。

本研究根据2009年陕西省森林资源清查资料中 公布的森林植被类型信息, 于 2012 年在全省布设 121 个覆盖主要植被类型的研究样点(图1), 主要包括落 叶松(Larix gmelinii)林、油松林、华山松(Pinus armandii)林、马尾松(P. massoniana)林、柏木(Cupressus funebris)林、辽东栋(Quercus wutaishanica) 


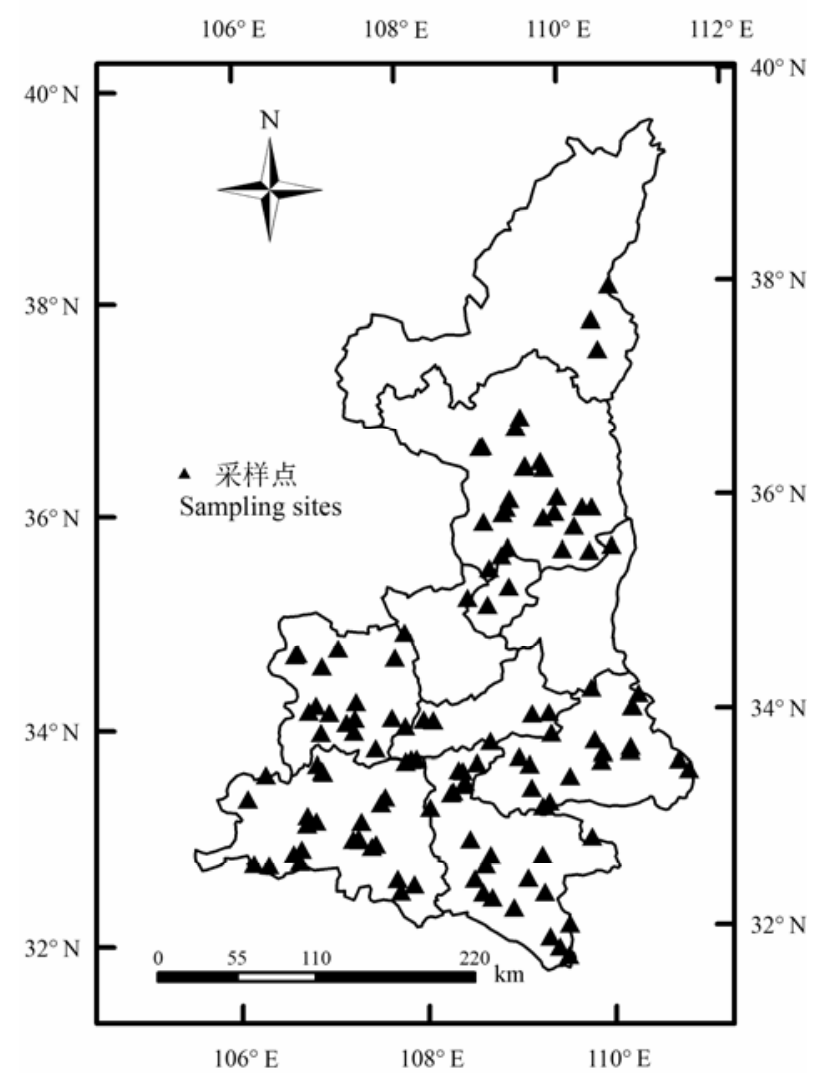

图1 陕西省采样点分布图。

Fig. 1 Distribution of sampling sites in the Shaanxi Province.

林、麻栋(Q. acutissima)林、栓皮栎林、白桦(Betula platyphylla)林、刺槐林等。其中, 刺槐林、油松林、 栎类林(辽东栋、栓皮栋等)为陕西省主要森林类型, 三者占到全省森林面积的 $72.64 \%$ 。其林下灌草层主 要物种组成是: 刺槐林主要物种有胡颓子 (Elaeagnus pungens)、铁杆蒿(Tripolium vulgare)、长 茅草(Stipa bungeana)、披针薹草(Carex lanceolata); 油松林主要物种有黄刺玫(Rosa xanthina)、柔毛绣线 菊(Spiraea pubescens)、连趐(Forsythia suspensa)、 甘菊(Dendranthema lavandulifolium)、茜草(Rubia cordifolia); 栎类林主要物种有虎榛子(Ostryopsis davidiana)、栓翅卫茅(Euonymus phellomanes)、英蒾 (Viburnum dilatatum)、大油芒(Spodiopogon sibiricus) 等。

采样点均选择在人为干扰较少且植被分布均匀, 乔、灌、草齐全, 区域代表性较强的地区。在每个 研究样点选取 3 个重复样地, 每个样地设置一个大 小为 $20 \mathrm{~m} \times 30 \mathrm{~m}$ 的样方, 并记录所在地地形、地貌
等环境因子。每个样方内设置 3 个 $2 \mathrm{~m} \times 2 \mathrm{~m}$ 的灌木 小样方, 在每个灌木小样方内设置一个 $1 \mathrm{~m} \times 1 \mathrm{~m}$ 的 草本小样方; 在样方内另外随机设置 3 个 $1 \mathrm{~m} \times 1 \mathrm{~m}$ 的枯落物小样方。

\section{2 样品采集与处理}

对样方内所有乔木每木检尺, 并采集优势树种 各器官样品。全收获法收集林下灌草(地上和地下)、 枯落物小样方内的样品, 同时取一部分灌草、枯落 物小样方内各器官混合样品用于 $\mathrm{N} 、 \mathrm{P}$ 含量及含水率 的测定。在每个样方内另取 3 个 $1 \mathrm{~m}$ 深的土芯(分为 $0-10 、 10-20 、 20-30 、 30-50 、 50-100 \mathrm{~cm}$ 等5层, 每 层混合取样)用于各层土壤全氮、全磷含量的测定; 同时挖取一个 $1 \mathrm{~m}$ 深的土壤剖面, 使用环刀法用于 相应土层容重的测定。以上各样品带回实验室后, 植物和枯落物样品烘干、粉碎后, 采用凯氏定氮法 和钼锑抗比色法测定全氮、全磷含量; 土壤样品则 风干磨碎后用凯氏法、硫酸-高氯酸消煮-钿锑抗比 色法(GB 7852-87)进行全氮、全磷含量的测定。

\section{3 数据分析}

各样方内乔木层、林下灌草层和枯落物层 $\mathrm{N} 、 \mathrm{P}$ 含量根据每层各器官相应 $\mathrm{N} 、 \mathrm{P}$ 含量进行质量加权平 均。计算公式如下:

$$
W_{i}=\frac{\sum_{j=1}^{n} C_{i j} \times B D_{i j}}{\sum_{j=1}^{n} B D_{i j}}
$$

其中 $W_{i}$ 为 $i$ 层 $(i$ 对应乔木、灌木、草本、枯落物层) 全氮、全磷含量 $\left(\mathrm{mg} \cdot \mathrm{g}^{-1}\right), C_{i j} 、 B D_{i j}$ 为 $i$ 层 $j$ 器官对应的 全氮、全磷含量 $\left(\mathrm{mg} \cdot \mathrm{g}^{-1}\right)$ 及生物量密度 $\left(\mathrm{g} \cdot \mathrm{m}^{-2}\right)$ 。当 $i$ 为乔木层时, $n=4, j=$ 叶、枝、干、根; 当 $i$ 为灌木层 时, $n=3, j=$ 叶、枝、根; 当 $i$ 为草本层时, $n=2, j=$ 叶、根。生物量密度为单位样方面积内某一器官的 生物量总和。其中, 乔木层各器官生物量密度是先 用适合于本地区各树种的异速生长方程求得样方中 每木该器官生物量, 然后累加得到整个样方的该器 官生物量, 再除以样方面积而来; 灌木层、草本层 各器官生物量密度, 则是由全收获法测算的各小样 方该器官生物量与该器官含水率换算而来的生物量 干质量除以样方面积而来; 枯落物层取样因未区分 各器官, 故以该层最终混合样品测得的全氮全磷含 量为该层氮磷加权平均含量。

土壤层 $(0-1 \mathrm{~m})$ 全氮、全磷含量采用下式计算: 


$$
T=\frac{\sum_{i=1}^{5} C_{i} \times B_{i} \times D_{i}}{\sum_{i=1}^{5} B_{i} \times D_{i}}
$$

其中, $T$ 为样方土层 $(0-1 \mathrm{~m})$ 全氮、全磷含量 $\left(\mathrm{mg} \cdot \mathrm{g}^{-1}\right)$, $C_{i} 、 B_{i}$ 和 $D_{i}$ 分别为第 $i$ 层土壤全氮全磷含量 $\left(\mathrm{mg} \cdot \mathrm{g}^{-1}\right)$ 、 容重 $\left(\mathrm{g} \cdot \mathrm{cm}^{-3}\right)$ 和深度 $(\mathrm{cm})(i=1-5$, 分别代表 $0-10$ 、 10-20、20-30、30-50、50-100 cm土层)。同一样点 3 个重复样地的平均值作为各森林类型该样点各生 态系统组分氮磷含量值。

使用SPSS 17.0统计软件对所有数据进行分析。 其中, 单因素方差分析用于生态系统各组分氮磷化 学计量的差异性检验, 并使用最小显著差数 $(L S D)$ 法进行多重比较; Pearson相关分析用于各组分间化 学计量特征的相关关系检验; 各组分氮磷化学计量 特征的空间分布分析则以经纬度和海拔为自变量, 各组分氮磷含量及氮磷比为因变量, 采用线性回归 进行分析。使用SigmaPlot 10.0软件进行图形绘制。

\section{2 结果}

\section{1 陕西省森林生态系统各组分的 N、P化学计量 特征}

生态系统各组分 $\mathrm{N} 、 \mathrm{P}$ 含量变化规律较为相似, 均以灌草层和枯落物层较高, 土壤层和乔木层较低 (图2A、2B)。其中 $\mathrm{N}$ 含量最高的组分为枯落物层 $\left(11.99 \mathrm{mg} \cdot \mathrm{g}^{-1}\right)$, 最低的为土壤层 $\left(0.72 \mathrm{mg} \cdot \mathrm{g}^{-1}\right)$, 各组 分间差异显著 $(p<0.05) ; \mathrm{P}$ 含量以草本层 $(1.07$ $\left.\mathrm{mg} \cdot \mathrm{g}^{-1}\right)$ 最高, 土壤层 $\left(0.47 \mathrm{mg} \cdot \mathrm{g}^{-1}\right)$ 最低。各组分 $\mathrm{N}: \mathrm{P}$ 值与 $\mathrm{N}$ 含量表现大致类似, 最高值和最低值分别出 现在枯落物层(14.84)和土壤层(1.86), 而乔木层和 灌草层 $\mathrm{N}: \mathrm{P}$ 值差异不显著 $(p>0.05)$ (图2C)。

土壤各层中, $\mathrm{N}$ 含量和 $\mathrm{N}: \mathrm{P}$ 值差异显著 $(p<0.05)$, 均随着土层加深呈现降低趋势; 但 $\mathrm{P}$ 含量各层间差 异不大, 均未达到显著性水平 $(p<0.05$ )(图2D、2E、 $2 \mathrm{~F})$ 。 $\mathrm{N} 、 \mathrm{P}$ 含量和 $\mathrm{N}: \mathrm{P}$ 值变化范围分别为 $0.47-1.72$ $\mathrm{mg} \cdot \mathrm{g}^{-1} 、 0.45-0.51 \mathrm{mg} \cdot \mathrm{g}^{-1}$ 和1.29-3.17。

2.2 陕西省针叶林和阔叶林 $N 、 P$ 化学计量特征的 比较

将森林划分为针叶林和阔叶林, 并对其 $\mathrm{N} 、 \mathrm{P}$ 计 量特征进行统计分析。由表1可知, 乔木层和枯落物 层 $\mathrm{N} 、 \mathrm{P}$ 含量, 灌木层 $\mathrm{N}$ 含量和草本层 $\mathrm{P}$ 含量均表现为 阔叶林高于针叶林 $(p<0.05)$, 其他各组分 $\mathrm{N} 、 \mathrm{P}$ 含量
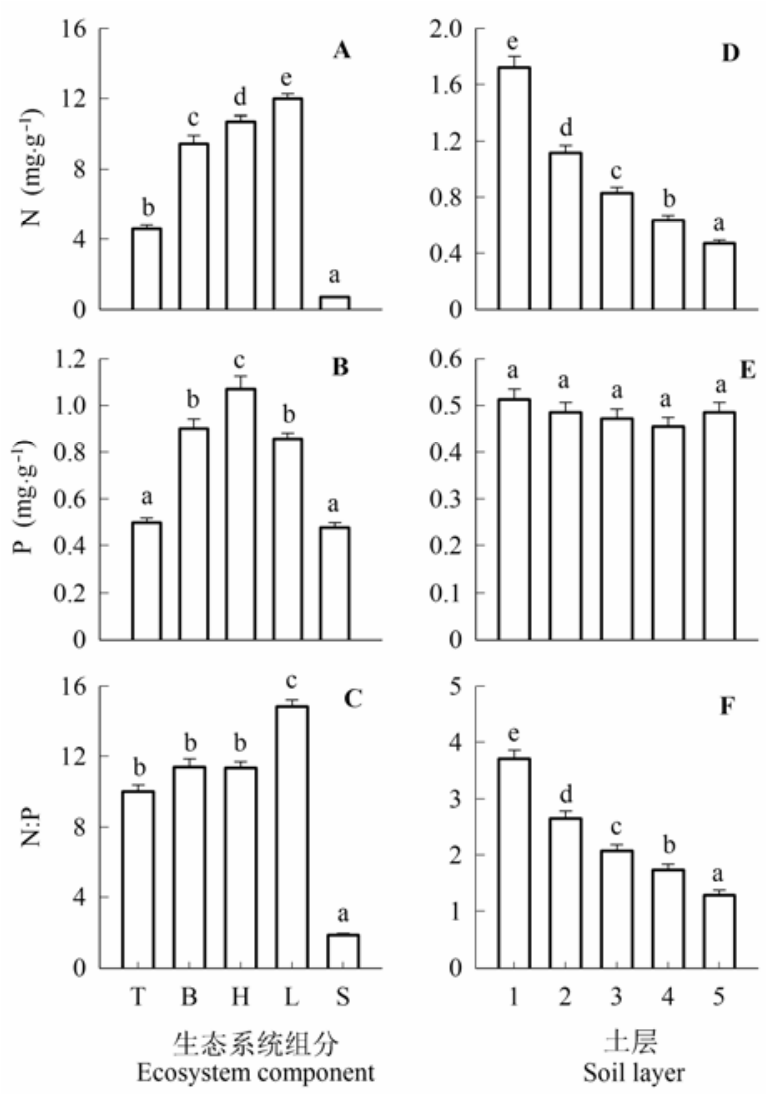

图2 陕西省森林生态系统各组分 $(A 、 B 、 C)$ 及土壤各层 $(D 、$ E、F)氮磷含量及氮磷比。 T、B、H、L和S分别代表乔木、 灌木、草本、枯落物和土壤; 图 $2 \mathrm{~F}$ 中 $X$ 轴上的 $1 、 2 、 3 、 4 、 5$ 分别代表0-10、10-20、20-30、30-50和50-100 cm土层。不 同小写字母代表差异性显著 $(p<0.05)$ 。误差线表示标准误 差。

Fig. $2 \mathrm{~N}$ and $\mathrm{P}$ concentrations and their ratio of each component in forest ecosystem (A, B, C) and in each layer of soil (D, E, F) in Shaanxi Province. T, B, H, L and S represent tree, bush, herb, litter and soil, respectively. $1,2,3,4$ and 5 at the $X$-axis of Fig. $2 F$ represent $0-10,10-20,20-30,30-50$ and $50-100 \mathrm{~cm}$ soil layers, respectively. Different lowercase letters indicate significant differences $(p<0.05)$. The error bars express standard error of the mean.

尽管表现类似, 但差异均未达到显著性水平 $(p>$ $0.05)$ 。各组分 $\mathrm{N}: \mathrm{P}$ 值只有在草本层中针叶林高于阔 叶林, 其他各组分两种林型间 $\mathrm{N}: \mathrm{P}$ 值相似(表1)。

此外, 对3种具有代表性的森林类型来说, 刺槐 林植被层和枯落物层 $\mathrm{N} 、 \mathrm{P}$ 含量高于油松和栓皮柇林, 而 $\mathrm{N}: \mathrm{P}$ 值则相差较小(图3A、3B、3C、3D)。对于土 壤 $\mathrm{N} 、 \mathrm{P}$ 计量特征而言, 3 种森林类型表现一致(图 $3 \mathrm{E})$ 。

2.3 陕西省森林生态系统各组分 $N 、 P$ 化学计量特 征的相关性

森林生态系统各组分间 $N$ Ｐ化学计量特征表现 
表1 陕西省针叶林、阔叶林生态系统各组分氮磷含量及氮磷比(平均值土标准误差)

Table $1 \mathrm{~N}$ and P content and their ratio of ecosystem components within broadleaf forest and coniferous forest in Shaanxi Province (mean \pm SE)

\begin{tabular}{|c|c|c|c|c|c|c|}
\hline \multirow{2}{*}{$\begin{array}{l}\text { 生态系统组分 } \\
\text { Ecosystem component }\end{array}$} & \multicolumn{2}{|c|}{$\mathrm{N}$} & \multicolumn{2}{|c|}{$\mathrm{P}$} & \multicolumn{2}{|c|}{$\mathrm{N}: \mathrm{P}$} \\
\hline & $\begin{array}{c}\text { 阔叶林 } \\
\text { Broadleaf forest } \\
\end{array}$ & $\begin{array}{c}\text { 针叶林 } \\
\text { Coniferous forest } \\
\end{array}$ & $\begin{array}{c}\text { 阔叶林 } \\
\text { Broadleaf forest } \\
\end{array}$ & $\begin{array}{c}\text { 针叶林 } \\
\text { Coniferous forest } \\
\end{array}$ & $\begin{array}{c}\text { 阔叶林 } \\
\text { Broadleaf forest } \\
\end{array}$ & $\begin{array}{c}\text { 针叶林 } \\
\text { Coniferous forest }\end{array}$ \\
\hline 乔木 Tree & $4.91 \pm 0.28^{\mathrm{A}}$ & $3.51 \pm 0.19^{B}$ & $0.52 \pm 0.02^{\mathrm{A}}$ & $0.38 \pm 0.02^{\mathrm{B}}$ & $10.21 \pm 0.46^{\mathrm{A}}$ & $9.41 \pm 0.46^{\mathrm{A}}$ \\
\hline 灌木 Bush & $10.09 \pm 0.53^{\mathrm{A}}$ & $7.33 \pm 0.79^{\mathrm{B}}$ & $0.92 \pm 0.04^{\mathrm{A}}$ & $0.80 \pm 0.08^{\mathrm{A}}$ & $11.73 \pm 0.50^{\mathrm{A}}$ & $10.24 \pm 1.18^{\mathrm{A}}$ \\
\hline 草本 Herb & $10.83 \pm 0.40^{\mathrm{A}}$ & $10.25 \pm 0.47^{\mathrm{A}}$ & $1.12 \pm 0.06^{\mathrm{A}}$ & $0.86 \pm 0.06^{\mathrm{B}}$ & $10.75 \pm 0.36^{\mathrm{A}}$ & $13.40 \pm 1.03^{\mathrm{B}}$ \\
\hline 枯落物 Litter & $12.68 \pm 0.32^{\mathrm{A}}$ & $9.47 \pm 0.35^{\mathrm{B}}$ & $0.89 \pm 0.02^{\mathrm{A}}$ & $0.72 \pm 0.05^{\mathrm{B}}$ & $14.85 \pm 0.40^{\mathrm{A}}$ & $14.78 \pm 1.03^{\mathrm{A}}$ \\
\hline 土壤 Soil & $0.73 \pm 0.03^{\mathrm{A}}$ & $0.66 \pm 0.06^{\mathrm{A}}$ & $0.53 \pm 0.05^{\mathrm{A}}$ & $0.41 \pm 0.03^{\mathrm{A}}$ & $1.84 \pm 0.11^{\mathrm{A}}$ & $1.92 \pm 0.20^{\mathrm{A}}$ \\
\hline
\end{tabular}

针叶林和阔叶林的样地数分别为 26 和 95 。相邻两列同行不同字母表示差异显著 $(p<0.05)$ 。

The plots for coniferous forest and broadleaf forest are 26 and 95, respectively. Different letters in the same row of adjacent columns for a given variable indicate significant difference at the level of 0.05 .
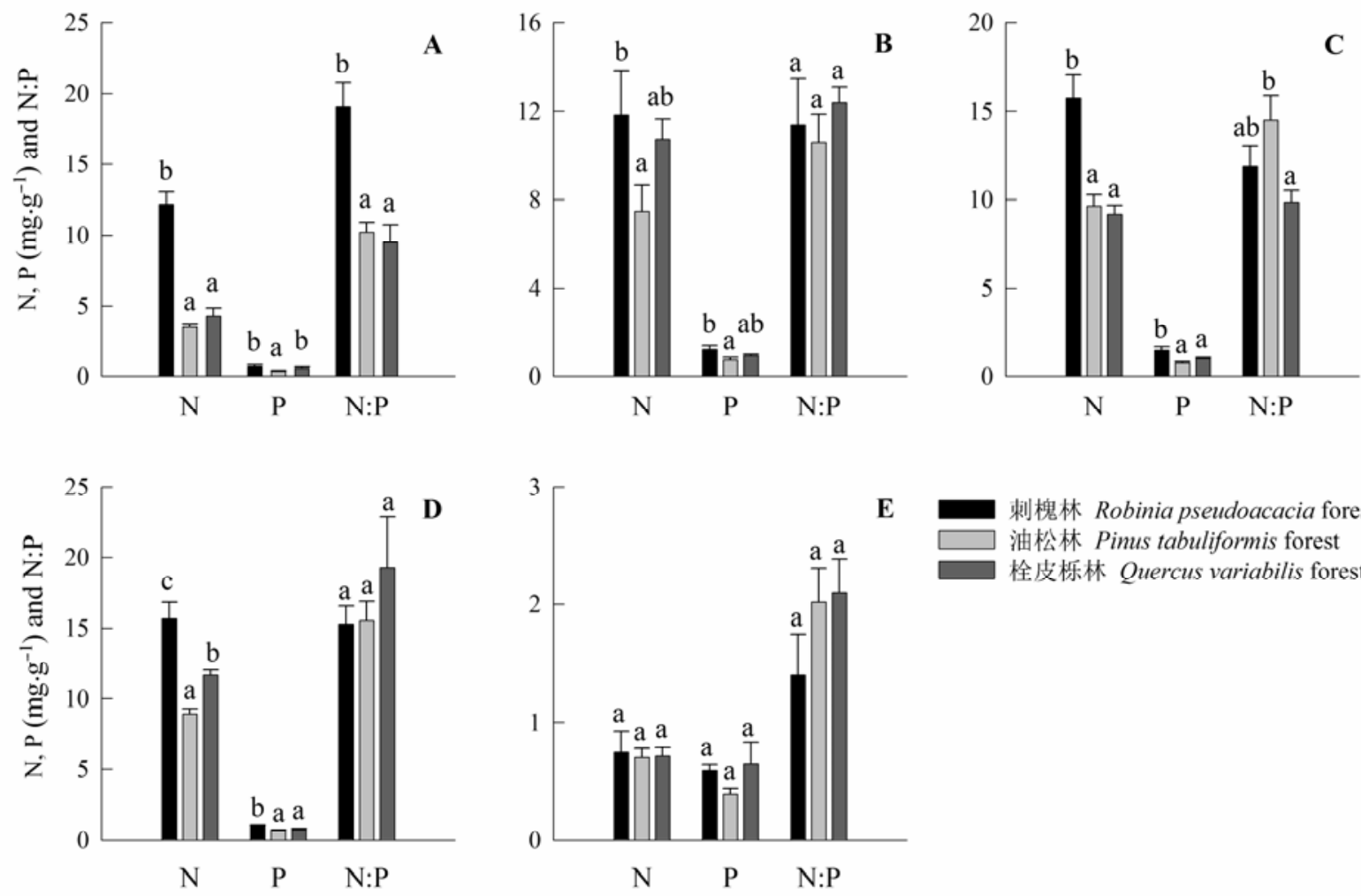

E

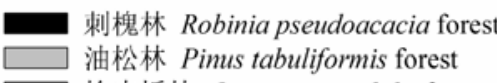

栓皮栋林 Quercus variabilis forest

图3 陕西省3种主要森林生态系统乔木 $(\mathbf{A}) 、$ 灌木 $(\mathbf{B}) 、$ 草本 $(\mathbf{C}) 、$ 枯落物(D)、土壤(E)各组分氮磷化学计量特征。刺槐林、油 松林和栓皮柇林的重复样本数分别为12、13和 25 。不同小写字母代表差异性显著 $(p<0.05)$ 。误差线表示标准误差。

Fig. $3 \mathrm{~N}$ and P concentrations and their ratio of tree (A), bush (B), herb (C), litter (D), soil (E) in three forest ecosystems in Shanxi Province. The number of sampling plot for Robinia pseudoacacia forest, Pinus tabuliformis forest and Quercus variabilis forest was 12,13 , and 25, respectively. Different lowercase letters indicate significant differences among forest types $(p<0.05)$. The error bars express standard error of the mean.

出显著的相关性, 其中枯落物层与乔木层、草本层、 土壤层的 $\mathrm{N} 、 \mathrm{P}$ 含量和 $\mathrm{N}: \mathrm{P}$ 值均呈极显著的正相关关 系, 且以与草本层的相关性最高 $\left(r_{\mathrm{N}}=0.45, r_{\mathrm{P}}=0.45\right.$, $\left.r_{\mathrm{N}: \mathrm{P}}=0.34\right)$; 但枯落物层与灌木层并未表现出显著 的相关关系(表2)。生态系统同一组分内 N、P相关性 也很紧密, 乔木层、灌草层、枯落物层各层内 $\mathrm{N} 、 \mathrm{P}$
之间均表现出极显著的正相关关系, 而土壤层 $\mathrm{N} 、 \mathrm{P}$ 间无显著相关性; 各组分 $\mathrm{N}: \mathrm{P}$ 值也分别与 $\mathrm{N}$ 含量和 $\mathrm{P}$ 含量呈现出极显著的正相关和负相关关系(表3)。

\section{4 陕西省森林生态系统各组分 $N 、 P$ 化学计量关 系的空间变异 \\ 对森林生态系统各组分 $N 、 P$ 化学计量进行空间}


表2 陕西省森林生态系统枯落物层与其他各组分氮磷化学计量相关性 Table 2 Correlation relationship of $\mathrm{N}$ and $\mathrm{P}$ stoichiometry between litter and tree, bush, herb and soil components in forest ecosystem in Shaanxi Province

\begin{tabular}{llcl}
\hline & \multicolumn{3}{c}{ 枯落物层 Litter layer } \\
\cline { 2 - 4 } & \multicolumn{1}{c}{$\mathrm{N}$} & $\mathrm{P}$ & $\mathrm{N}: \mathrm{P}$ \\
\hline 乔木层 Tree layer & $0.29^{* *}$ & $0.36^{* * *}$ & $0.28^{* *}$ \\
灌木层 Bush layer & 0.08 & -0.10 & 0.01 \\
草本层 Herb layer & $0.45^{* * *}$ & $0.45^{* * *}$ & $0.34^{* * *}$ \\
土壤层 Soil layer & $0.28^{* *}$ & $0.32^{* * *}$ & $0.30^{* *}$ \\
\hline$* *, p<0.01 ; * * *, p<0.001$. & &
\end{tabular}

表3 陕西省森林生态系统各组分内氮磷化学计量相关性

Table 3 Correlation relationships of $\mathrm{N}$ and $\mathrm{P}$ stoichiometry within tree, bush, herb, litter and soil components in forest ecosystem in Shaanxi Province

\begin{tabular}{ccccccc}
\hline & $n$ & \multicolumn{5}{c}{$\mathrm{N}: \mathrm{P}$} \\
\cline { 3 - 7 } & & $\begin{array}{c}\text { 乔木层 } \\
\text { Tree layer }\end{array}$ & $\begin{array}{c}\text { 灌木层 }^{1)} \\
\text { Bush layer }\end{array}$ & $\begin{array}{c}\text { 草本层 } \\
\text { Herb layer }\end{array}$ & $\begin{array}{c}\text { 枯落物层 } \\
\text { Litter layer }\end{array}$ & $\begin{array}{c}\text { 土壤层 } \\
\text { Soil layer }\end{array}$ \\
\hline $\mathrm{N}$ & 121 & $0.58^{* * *}$ & $0.57^{* * *}$ & 0.17 & $0.32^{* * *}$ & $0.55^{* * *}$ \\
$\mathrm{P}$ & 121 & $-0.40^{* * *}$ & $-0.39^{* * *}$ & $-0.58^{* * *}$ & $-0.70^{* * *}$ & $-0.66^{* * *}$ \\
$r$ & 121 & $0.42^{* * *}$ & $0.42^{* * *}$ & $0.54^{* * *}$ & $0.36^{* * *}$ & 0.10
\end{tabular}

$r$ 代表各组分内氮磷间的相关系数, 1)其中 15 个样点林下没有灌木分布, 其样本数为 106 。 $* * *, p<0.001$ 。

$r$ represents the correlation coefficient between $\mathrm{N}$ and $\mathrm{P}$ concentration of each component. 1) The plots for bush layer are 106 with 15 sampling sites where bush are not distributed. ***, $p<0.001$.

分布分析发现，尽管个别组分氮磷计量呈现一定的 空间变化模式, 例如草本层N、P含量随经度增加而 降低, 乔木层 $\mathrm{N}$ 含量和 $\mathrm{N}: \mathrm{P}$ 值随纬度增加而增加, 灌 木层 $\mathrm{P}$ 含量、枯落物层和土壤层的 $\mathrm{N}: \mathrm{P}$ 值随纬度增加 而减小, 土壤层 $\mathrm{N}$ 含量、 $\mathrm{N}: \mathrm{P}$ 值随海拔升高而增加, 但总体上来说, 各组分 $N$ 、P含量及 $\mathrm{N}: \mathrm{P}$ 值大多表现 平稳, 并不随经纬度和海拔发生显著变化(表4)。

\section{3 讨论}

\section{1 陕西省森林生态系统氮磷化学计量特征}

本研究着重分析了陕西省森林生态系统植被层 (乔木层、灌木层和草本层)、枯落物层和土壤各组 分的 $\mathrm{N} 、 \mathrm{P}$ 化学计量特征及其相关关系。结果表明: 与单一叶片器官水平相比, 植物全株水平表现出不 同的 $\mathrm{N} 、 \mathrm{P}$ 化学计量特征。陕西省森林植被乔木层、 灌木层和草本层 $\mathrm{N} 、 \mathrm{P}$ 含量和 $\mathrm{N}: \mathrm{P}$ 值分别介于 4.59-10.70 mg $\cdot \mathrm{g}^{-1} 、 0.49-1.07 \mathrm{mg} \cdot \mathrm{g}^{-1}$ 和10.03-11.38 之间, 分别小于对应各层植物叶片的测定值, 同时 也低于Zheng和Shangguan (2007)对黄土高原126份 植物叶片样品的测定值 $\left(\mathrm{N}=24.1 \mathrm{mg} \cdot \mathrm{g}^{-1} 、 \mathrm{P}=1.6\right.$ $\mathrm{mg} \cdot \mathrm{g}^{-1} 、 \mathrm{~N}: \mathrm{P}$ 值= 15.4), 以及任书杰等(2007)和Han
等(2005)在全国, Reich和Oleksyn (2004)以及Elser等 (2000a) 在全球尺度对植物叶片 N、P养分计量特征的 研究结果(表5)。引起这种差异的原因在于叶片作为 重要的养分储存器官, N、P含量远远高于其他器官 (Minden \& Kleyer, 2014), 而叶片相比其他器官所 占生物量比重较低(本研究中叶片仅占总生物量的 $10 \%$ 左右), 所以导致全株 $\mathrm{N} 、 \mathrm{P}$ 含量低于叶片。此外, 对不同生活型植物 $\mathrm{N} 、 \mathrm{P}$ 含量而言, 乔木层低于林下 灌草层(图2), 针叶林低于阔叶林(表1), 这与以往的 研究结果(Han et al., 2005; Wright et al., 2005)一致。 以上结果说明不同植物的养分利用策略不同，与木 本植物相比, 寿命短的草本植物更加注重将养分用 于植物的快速生长(Zheng \& Shangguan, 2007), 针 叶林则更多地将养分投入到构建保卫构造(McGroddy et al., 2004)。

刺槐和油松作为陕西省植被恢复的代表性树种 在20世纪得到了大面积推广, 在持水固土、碳固持 等方面取得了良好的生态效益。本文将刺槐和油松 与典型天然次生栓皮柇林的化学计量特征进行对比 分析, 发现刺槐林植被层和枯落物层的 $\mathrm{N}$ 含量均高 于油松林和栓皮栎林, 这与刺槐作为豆科植物所特 有的固氮作用有很大关系。同时, 刺槐林各组分 $\mathrm{P}$ 含量相应地也高于其他两种林分, 而最终各组分 $\mathrm{N}: \mathrm{P}$ 值却相差不大，说明了植物 $\mathrm{N}$ 和 $\mathrm{P}$ 之间存在着高 度的协同性, 是植物氮磷化学计量内稳性的重要表 现。这种协同性不仅存在于不同树种间, 在系统的 不同组分间同样存在, 比如对植被层而言, 尽管植 被层内各组分氮磷含量存在显著性差异 $(p<0.05)$, 但其 $\mathrm{N}: \mathrm{P}$ 值却一致(图1)。

土壤层 $\mathrm{N} 、 \mathrm{P}$ 间则不存在协同性。其中, 土壤 $\mathrm{N}$ 、 $\mathrm{N}: \mathrm{P}$ 值随深度增加而降低, 土壤则不随深度发生变 化(图2), 这主要与土壤氮磷来源差异有关。土壤全 氮主要来源于枯落物和植物根系分解形成的有机质, 植物残体和地下植物根系主要分布于土壤表层, 随 着土壤深度增加而减少, 故全氮含量随着土层加深 而降低。土壤全磷的来源则不同于土壤全氮, 主要 源于岩石风化。且P素作为一种沉积性的矿物, 在土 壤中的迁移率很低, 因此全P在整个空间中的分布 较为均匀, 随土壤深度变化不大, 故而造成 $\mathrm{N}: \mathrm{P}$ 值 随土壤深度增加而降低。

$\mathrm{N} 、 \mathrm{P}$ 作为陆地生态系统的限制性营养元素, 其 比率通常被用作描述群落 $\mathrm{N}$ 和 $\mathrm{P}$ 的相对限制状况 
表4＼cjkstart陕西省森林生态系统各组分氮磷化学计量随经纬度和海拔空间变化分析

Table 4 Spatial pattern analysis of $\mathrm{N}$ and P stoichiometry within ecosystem component in relation to latitude, longitude, and elevation in Shaanxi Province

\begin{tabular}{|c|c|c|c|c|c|c|c|c|c|c|c|}
\hline & \multirow{2}{*}{$\begin{array}{l}\text { 生态系统组分 } \\
\text { Ecosystem component }\end{array}$} & \multirow[t]{2}{*}{$n$} & \multicolumn{3}{|c|}{$\mathrm{N}$} & \multicolumn{3}{|c|}{$\mathrm{P}$} & \multicolumn{3}{|c|}{$\mathrm{N}: \mathrm{P}$} \\
\hline & & & 斜率 Slope & $R^{2}$ & $p$ & 斜率 Slope & $R^{2}$ & $p$ & 斜率 Slope & $R^{2}$ & $p$ \\
\hline 经度 & 乔木层 Tree layer & 121 & 0.02 & 0.001 & 0.80 & -0.03 & 0.001 & 0.72 & -0.04 & 0.001 & 0.70 \\
\hline \multirow[t]{4}{*}{ Longitude } & 灌木层 Bush layer* & 106 & 0.04 & 0.001 & 0.71 & 0.03 & 0.001 & 0.76 & 0.02 & $<0.001$ & 0.88 \\
\hline & 草本层 Herb layer & 121 & -0.12 & 0.03 & 0.05 & -0.26 & 0.07 & 0.004 & 0.16 & 0.03 & 0.07 \\
\hline & 枯落物层 Litter layer & 121 & -0.08 & 0.006 & 0.42 & -0.18 & 0.03 & 0.05 & 0.10 & 0.01 & 0.25 \\
\hline & 土壤层 Soil layer & 121 & -0.06 & 0.004 & 0.51 & 0.02 & 0.001 & 0.80 & -0.02 & 0.001 & 0.80 \\
\hline 纬度 & 乔木层 Tree layer & 121 & 0.33 & 0.11 & $<0.001$ & 0.02 & $<0.001$ & 0.86 & 0.22 & 0.05 & 0.01 \\
\hline \multirow[t]{4}{*}{ Latitude } & 灌木层 Bush layer* & 106 & -0.10 & 0.01 & 0.30 & -0.22 & 0.05 & 0.02 & 0.02 & 0.001 & 0.80 \\
\hline & 草本层 Herb layer & 121 & -0.07 & 0.004 & 0.47 & -0.15 & 0.02 & 0.11 & 0.14 & 0.02 & 0.12 \\
\hline & 枯落物层 Litter layer & 121 & -0.11 & 0.01 & 0.22 & 0.07 & 0.004 & 0.47 & -0.18 & 0.03 & 0.04 \\
\hline & 土壤层 Soil layer & 121 & -0.13 & 0.02 & 0.17 & 0.17 & 0.03 & 0.06 & -0.39 & 0.15 & $<0.001$ \\
\hline 海拔 & 乔木层 Tree layer & 121 & 0.01 & $<0.001$ & 0.92 & -0.09 & 0.01 & 0.31 & 0.11 & 0.01 & 0.19 \\
\hline \multirow[t]{4}{*}{ Elevation } & 灌木层 Bush layer* & 106 & 0.02 & $<0.001$ & 0.86 & 0.06 & 0.003 & 0.57 & -0.01 & $<0.001$ & 0.89 \\
\hline & 草本层 Herb layer & 121 & 0.09 & 0.007 & 0.35 & -0.04 & 0.002 & 0.66 & $<0.001$ & $<0.001$ & 0.99 \\
\hline & 枯落物层 Litter layer & 121 & 0.17 & 0.03 & 0.06 & -0.02 & $<0.001$ & 0.82 & 0.06 & 0.004 & 0.47 \\
\hline & 土壤层 Soil layer & 121 & 0.48 & 0.23 & $<0.001$ & -0.03 & 0.001 & 0.73 & 0.21 & 0.04 & 0.02 \\
\hline
\end{tabular}

表中数字加粗表示标准化回归系数(斜率)达到显著性水平 $(p<0.05)$; *, 其中15个样点林下没有灌木分布。

Slopes statistically significant are indicated in bold type $(p<0.05)$; *, there are 15 sampling sites where bush are not distributed.

表5＼cjkstart陕西省植被层氮磷化学计量特征与其他研究结果的比较

Table 5 Comparisons of $\mathrm{N}$ and P stoichiometric characteristics of vegetation in Shaanxi Province with others studies

\begin{tabular}{|c|c|c|c|c|}
\hline 类型 Types & $\mathrm{N}\left(\mathrm{mg} \cdot \mathrm{g}^{-1}\right)$ & $\mathrm{P}\left(\mathrm{mg} \cdot \mathrm{g}^{-1}\right)$ & $\mathrm{N}: \mathrm{P}$ & 文献 Reference \\
\hline 陕西省 乔木 Tree & 4.59 (121) & $0.49(121)$ & $10.03(121)$ & \\
\hline 乔木叶片 Tree leaf & $16.73(121)$ & $1.29(121)$ & $13.87(121)$ & \\
\hline 灌木 Bush ${ }^{1)}$ & $9.46(106)$ & $0.90(106)$ & $11.38(106)$ & This study \\
\hline 灌木叶片 Bush leaf & $13.54(106)$ & $1.08(106)$ & $13.52(106)$ & \\
\hline 草本 Herb & $10.70(121)$ & $1.07(121)$ & $11.32(121)$ & \\
\hline 草本叶片 Herb leaf & $14.66(121)$ & $1.38(121)$ & $12.17(121)$ & \\
\hline 黄土高原植物叶片 Plants leaf in Loess Plateau & $24.1(126)$ & $1.6(126)$ & $15.4(126)$ & Zheng \& Shangguan, 2007 \\
\hline 长白山针阔混交林 Changbai Shan needle broad-leaved mixed forest & $17.63(21)$ & $1.45(21)$ & $13.0(21)$ & Wang et al., 2011 \\
\hline 西双版纳热带季雨林 Xishuangbanna tropical monsoon forest & $21.49(36)$ & $1.05(36)$ & $19(36)$ & Wang et al., 2011 \\
\hline 鼎湖山南亚热带常绿阔叶林 Dinghushan subtropical evergreen broad-leaved forest & $19.82(21)$ & $1.02(21)$ & $22(21)$ & Wang et al., 2011 \\
\hline 中亚热带天童常绿阔叶林 Middle subtropical Tiantong evergreen broad-leaved forest & $11.5(14)$ & $0.63(14)$ & $17.8(14)$ & Yan et al., 2010 \\
\hline 中亚热带天童常绿针叶林 Middle subtropical Tiantong evergreen coniferous forest & $9.98(16)$ & $0.66(16)$ & $14.2(16)$ & Yan et al., 2010 \\
\hline 中亚热带天童落叶阔叶林 Middle subtropical Tiantong deciduous broad-leaved forest & $14.7(14)$ & $1.3(14)$ & $11.1(14)$ & Yan et al., 2010 \\
\hline 中国植物叶片 Chinese plants leaf & $19.09(554)$ & $1.56(647)$ & $15.39(546)$ & Ren et al., 2007 \\
\hline 中国植物叶片 Chinese plants leaf & $20.24(554)$ & $1.46(745)$ & $16.3(547)$ & Han et al., 2005 \\
\hline 全球植物叶片 Global plants leaf & $20.09(1251)$ & 1.77 (923) & $13.8(894)$ & Reich \& Oleksyn, 2004 \\
\hline 全球植物叶片 Global plants leaf & $20.62(398)$ & $1.99(406)$ & $12.7(325)$ & Elser et al., 2000a \\
\hline
\end{tabular}

括号内数字为研究样本数。1)其中15个样点林下没有灌木分布。

The numbers of samples are given in parentheses. 1) there are 15 sampling sites where bush are not distributed.

(Güsewell, 2004; Niklas et al., 2005)。本研究中植被 层叶片 $\mathrm{N}: \mathrm{P}$ 值与长白山针阔混交林相近, 却均低于 南方热带季雨林和亚热带常绿阔叶林(阎恩荣等, 2010; 王晶苑等, 2011), 也低于黄土高原(Zheng \&
Shangguan, 2007)、全国(Han et al., 2005; 任书杰等, 2007)、全球(Elser et al., 2000a; Reich \& Oleksyn, 2004)植物叶片测定值(表5)。这说明陕西省等北方森 林植被群落生长可能更多地受到 $\mathrm{N}$ 的限制, 因为陆

www.plant-ecology.com 
地生态系统中, 温带森林和北方森林土壤较为年轻 而更易受 $N$ 限制, 热带雨林中土壤风化时间长且淋 溶强度大, $\mathrm{P}$ 极为缺乏(Hedin et al., 2003; Reich \& Oleksyn, 2004)。在古尔班通古特沙漠(陶冶和张元明, 2015)和亚热带鼎湖山(刘兴诏等, 2010)的研究中也 发现北方土壤相对缺 $\mathrm{N}$, 而南方森林土壤相对缺 $\mathrm{P}$ 。 此外, 土壤层的 $\mathrm{N}: \mathrm{P}$ 值(1.86)远远低于植被层的 $\mathrm{N}: \mathrm{P}$ (10.03-11.38) (图1), 亦能从一定程度上反映出土壤 氮素相对磷素供应不足。当然, N:P值被用作营养元 素限制状况判断的指标, 其适用范围和临界阈值会 因生态系统类型和环境条件的改变而发生变化, 本 身具有一定的局限性, 未来应结合施肥试验进行进 一步的诊断(Güsewell, 2004)。

\section{2 森林生态系统氮磷化学计量空间分布分析}

有关生态系统的化学计量地理空间分布格局分 析目前受到了广泛关注, 不同的学者针对植物叶片 及根系分别在区域及全球尺度上开展了大量研究。 例如, Han等(2005)和任书杰等(2007)对中国叶片氮 磷化学计量特征进行空间分析研究, 表明叶片 N、P 含量随纬度增加而增加, 这与Reich和Oleksyn (2004) 在全球范围内针对 1280 种植物叶片的研究结果一 致, 也与马玉珠等(2015)有关中国细根的研究结果 相似。说明无论植物叶片还是细根均符合 “温度-植 物生理假说”, 即为抵消高纬度低温带来体内生化 反应减缓, 植物提高体内 $\mathrm{N} 、 \mathrm{P}$ 含量以增强代谢活动 和增大生长速率的一种生理适应机制(Reich et al., 1996; Oleksyn et al., 1998; Woods et al., 2003)。但本 研究中除乔木层氮含量与灌木层磷含量外, 其他各 组分氮磷含量均与纬度无明显相关性, 不随纬度而 发生变化, 与该假说不符。在Zheng和 Shangguan (2007)有关黄土高原植物叶片养分空间分布格局的 分析中也未发现存在纬度性分布规律。此外, Kerkhoff等(2005)在全球尺度上针对1 054种植物叶 片的研究认为 $\mathrm{N} 、 \mathrm{P}$ 含量与纬度变化没有明显的相关 性。

就N:P值而言, Reich和Oleksyn (2004)、Kerkhoff 等(2005)研究认为全球尺度叶片 N:P值随纬度增加 而降低, 两者间呈负相关关系。本研究中除枯落物 和土壤的 $N: P$ 值与纬度负相关外, 其他各组分 N:P值 则不存在这种负相关关系。这可能与本研究所涉及 的区域范围较小有关, 大尺度氮磷计量的宏观变化 规律在小尺度被其他影响因素所掩盖, 未能显现出
明显的分布模式。比如, 在Reich和Oleksyn (2004) 的研究中, 尽管叶片 $\mathrm{N} 、 \mathrm{P}$ 含量和 N:P值与年平均温 度和纬度呈现极显著的相关性, 但仍不能忽视这些 关系只有在全球尺度上才能显现出来, 若对其整个 纬度研究范围 $\left(43^{\circ} \mathrm{S}-70^{\circ} \mathrm{N}\right)$ 进行分段分析, 则各纬 度段内并没有显著变化规律, N、P化学计量只在各 纬度段间有差别, 也就意味着叶片氮磷化学计量其 实呈现出一种阶梯式分段变化。Townsend等(2007) 在巴西和哥斯达黎加的研究也发现, 热带地区冠层 叶片 $\mathrm{N}: \mathrm{P}$ 值并不与纬度或年降水量存在任何关系, 引起叶片 $\mathrm{N}: \mathrm{P}$ 值差异的更多是物种间的差别。这进 一步突出说明了在小区域范围内存在有除温度、降 雨外更为复杂的主导氮磷空间分布的因素。

森林生态系统各组分 $N$, P 化学计量与经度和垂 直海拔的空间分析大致与纬度变化表现相似, 基本 都不随经度和海拔发生变化, 具有一定的稳定性, 这与Han等(2011)、马玉珠等(2015)对中国植物叶片 和细根的研究结果不一致。鉴于 N、P化学计量空间 分布模式在全球及区域尺度所表现的不一致性, 有 待进一步深入研究N、P化学计量空间分布及其背后 所隐藏的深层影响作用机制, 深化对氮磷生物地球 化学循环的理解与认识。

\section{4 结论}

本文通过对陕西省森林生态系统各组分 $\mathrm{N} 、 \mathrm{P}$ 含 量及 $N$ : P值进行研究分析, 表明各组分间 N、P化学 计量显著正相关, 说明 $\mathrm{N} 、 \mathrm{P}$ 作为生态系统的重要营 养元素, 在森林植被、枯落物和土壤各组分间存在 着紧密的物质养分循环与流通。同时, 由于各组分 执行不同的生态功能, 导致其计量特征存在差异。 特别是对植被层(乔、灌、草)而言, N、P含量表现出 较高的协同性, 是植物氮磷化学计量内稳性的重要 体现。土壤由于 $\mathrm{N} 、 \mathrm{P}$ 来源的差异则不存在这种协同 性。阐明森林生态系统各组分间 N、P化学计量特征 及其相互关系对于理解系统内物质养分循环及其相 互作用具有一定的理论意义。然而, 鉴于各组分化 学计量空间分布所表现出的不一致性, 有必要进一 步加强对氮磷化学计量空间变异在区域尺度上影响 因素及其作用机制的研究。

基金项目 国家自然科学基金项目(41201088和 41371506)、中国科学院“西部之光”和中国科学院战 略性先导科技专项(XDA05050203-05)。 


\section{参考文献}

Bott T, Meyer GA, Young EB (2008). Nutrient limitation and morphological plasticity of the carnivorous pitcher plant Sarracenia purpurea in contrasting wetland environments. New Phytologist, 180, 631-641.

Chen YH, Han WX, Tang LY, Tang ZY, Fang JY (2013). Leaf nitrogen and phosphorus concentrations of woody plants differ in responses to climate, soil and plant growth form. Ecography, 36, 178-184.

Cleveland CC, Liptzin D (2007). C:N:P stoichiometry in soil: Is there a "Redfield ratio" for the microbial biomass? Biogeochemistry, 85, 235-252.

Elser JJ, Fagan WF, Denno RF, Dobberfuhl DR, Folarin A, Huberty A, Interlandi S, Kilham SS, McCauley E, Schulz KL, Siemann EH, Sterner RW (2000a). Nutritional constraints in terrestrial and freshwater food webs. Nature, 408, 578-580.

Elser JJ, Sterner RW, Gorokhova E, Fagan WF, Markow TA, Cotner JB, Harrison JF, Hobbie SE, Odell GM, Weider LW (2000b). Biological stoichiometry from genes to ecosystems. Ecology Letters, 3, 540-550.

Güsewell S (2004). N:P ratios in terrestrial plants: Variation and functional significance. New Phytologist, 164, 243266.

Han WX, Fang JY, Guo DL, Zhang Y (2005). Leaf nitrogen and phosphorus stoichiometry across 753 terrestrial plant species in China. New Phytologist, 168, 377-385.

Han WX, Fang JY, Reich PB, Ian Woodward F, Wang ZH (2011). Biogeography and variability of eleven mineral elements in plant leaves across gradients of climate, soil and plant functional type in China. Ecology Letters, 14, 788-796.

Hedin LO, Vitousek PM, Matson PA (2003). Nutrient losses over four million years of tropical forest development. Ecology, 84, 2231-2255.

Kerkhoff AJ, Enquist BJ, Elser JJ, Fagan WF (2005). Plant allometry, stoichiometry and the temperature-dependence of primary productivity. Global Ecology and Biogeography, 14, 585-598.

Li A, Guo DL, Wang ZQ, Liu HY (2010). Nitrogen and phosphorus allocation in leaves, twigs, and fine roots across 49 temperate, subtropical and tropical tree species: A hierarchical pattern. Functional Ecology, 24, 224-232.

Liu XZ, Zhou GY, Zhang DQ, Liu SZ, Chu GW, Yan JH (2010). N and P stoichiometry of plant and soil in lower subtropical forest successional series in southern China. Chinese Journal of Plant Ecology, 34, 64-71. (in Chinese with English abstract) [刘兴诏, 周国逸, 张德强, 刘世 忠, 褚国伟, 间俊华 (2010). 南亚热带森林不同演替阶 段植物与土壤中 $N$ 、P的化学计量特征. 植物生态学报, 34, 64-71.]

Ma YZ, Zhong QL, Jin BJ, Lu HD, Guo BQ, Zheng Y, Li M,
Cheng DL (2015). Spatial changes and influencing factors of fine root carbon, nitrogen and phosphorus stoichiometry of plants in China. Chinese Journal of Plant Ecology, 39, 159-166. (in Chinese with English abstract) [马玉珠, 钟 全林, 靳冰洁, 卢宏典, 郭炳桥, 郑媛, 李曼, 程栋梁 (2015). 中国植物细根碳、氮、磷化学计量学的空间变 化及其影响因子. 植物生态学报, 39, 159-166.]

Manzoni S, Trofymow JA, Jackson RB, Porporato A (2010). Stoichiometric controls on carbon, nitrogen, and phosphorus dynamics in decomposing litter. Ecological Monographs, 80, 89-106.

McGroddy ME, Daufresne T, Hedin LO (2004). Scaling of $\mathrm{C}: \mathrm{N}: \mathrm{P}$ stoichiometry in forests worldwide: Implications of terrestrial Redfield-type ratios. Ecology, 85, 2390-2401.

Minden V, Kleyer M (2014). Internal and external regulation of plant organ stoichiometry. Plant Biology, 16, 897-907.

Niklas KJ, Owens T, Reich PB, Cobb ED (2005). Nitrogen/phosphorus leaf stoichiometry and the scaling of plant growth. Ecology Letters, 8, 636-642.

Oleksyn J, Modrzýnski J, Tjoelker MG, Zytkowiak R, Reich PB, Karolewski P (1998). Growth and physiology of Picea abies populations from elevational transects: Common garden evidence for altitudinal ecotypes and cold adaptation. Functional Ecology, 12, 573-590.

Ordoñez JC, van Bodegom PM, Witte JPM, Wright IJ, Reich PB, Aerts R (2009). A global study of relationships between leaf traits, climate and soil measures of nutrient fertility. Global Ecology and Biogeography, 18, 137-149.

Reich PB, Oleksyn J (2004). Global patterns of plant leaf N and $\mathrm{P}$ in relation to temperature and latitude. Proceedings of the National Academy of Sciences of the United States of America, 101, 11001-11006.

Reich PB, Oleksyn J, Tjoelker MG (1996). Needle respiration and nitrogen concentration in Scots pine populations from a broad latitudinal range: A common garden test with field-grown trees. Functional Ecology, 10, 768-776.

Ren SJ, Yu GR, Tao B, Wang SQ (2007). Leaf nitrogen and phosphorus stoichiometry across 654 terrestrial plant species in NSTEC. Chinese Journal of Environmental Science, 28, 2665-2673. (in Chinese with English abstract) [任书杰, 于贵瑞, 陶波, 王绍强 (2007). 中国东部南北 样带654种植物叶片氮和磷的化学计量学特征研究. 环 境科学, 28, 2665-2673.]

Tao Y, Zhang YM (2015). Leaf and soil stoichiometry of four herbs in the Gurbantunggut Desert, China. Chinese Journal of Applied Ecology, 26, 659-665. (in Chinese with English abstract) [陶冶, 张元明 (2015). 古尔班通古特 沙漠4种草本植物叶片与土壤的化学计量特征. 应用生 态学报, 26, 659-665.]

Tian HQ, Chen GS, Zhang C, Melillo JM, Hall CAS (2010). Pattern and variation of C:N:P ratios in China's soils: A synthesis of observational data. Biogeochemistry, 98, 
139-151.

Townsend AR, Cleveland CC, Asner GP, Bustamante MMC (2007). Controls over foliar N:P ratios in tropical rain forests. Ecology, 88, 107-118.

Wang JY, Wang SQ, Li RL, Yan JH, Sha LQ, Han SJ (2011). $\mathrm{C}: \mathrm{N}: \mathrm{P}$ stoichiometric characteristics of four forest types' dominant tree species in China. Chinese Journal of Plant Ecology, 35, 587-595. (in Chinese with English abstract) [王晶苑, 王绍强, 李㧅兰, 间俊华, 沙丽清, 韩士杰 (2011). 中国四种森林类型主要优势植物的C:N:P化学 计量学特征. 植物生态学报, 35, 587-595.]

Wang M, Moore TR (2014). Carbon, nitrogen, phosphorus, and potassium stoichiometry in an ombrotrophic peatland reflects plant functional type. Ecosystems, 17, 673-684.

Wang SQ, Yu GR (2008). Ecological stoichiometry characteristics of ecosystem carbon, nitrogen and phosphorus elements. Acta Ecologica Sinica, 28, 3937-3947. (in Chinese with English abstract) [王绍强, 于贵瑞 (2008). 生态系 统碳氮磷元素的生态化学计量学特征. 生态学报, 28, 3937-3947.]

Woods HA, Makino W, Cotner JB, Hobbie SE, Harrison JF, Acharya K, Elser JJ (2003). Temperature and the chemical composition of poikilothermic organisms. Functional Ecology, 17, 237-245.

Wright IJ, Reich PB, Cornelissen JHC, Falster DS, Garnier E,
Hikosaka K, Lamont BB, Lee W, Oleksyn J, Osada N, Poorter H, Villar R, Warton DI, Westoby M (2005). Assessing the generality of global leaf trait relationships. New Phytologist, 166, 485-496.

Yan ER, Wang XH, Guo M, Zhong Q, Zhou W (2010). C:N:P stoichiometry across evergreen broad-leaved forests, evergreen coniferous forests and deciduous broad-leaved forests in the Tiantong region, Zhejiang Province, eastern China. Chinese Journal of Plant Ecology, 34, 48-57. (in Chinese with English abstract) [阎恩荣, 王希华, 郭明, 仲强, 周武 (2010). 浙江天童常绿阔叶林、常绿针叶林 与落叶阔叶林的 C: $\mathrm{N}: \mathrm{P}$ 化学计量特征. 植物生态学报, 34, 48-57.]

Yuan ZY, Chen HYH (2012). A global analysis of fine root production as affected by soil nitrogen and phosphorus. Proceedings of the Royal Society B: Biological Sciences, 279, 3796-3802.

Yuan ZY, Chen HYH, Reich PB (2011). Global-scale latitudinal patterns of plant fine-root nitrogen and phosphorus. Nature Communications, 2, 344.

Zheng SX, Shangguan ZP (2007). Spatial patterns of leaf nutrient traits of the plants in the Loess Plateau of China. Trees, 21, 357-370.

责任编委: 阎恩荣 责任编辑: 王 葳 